\title{
Lista publikacji prof. dr hab. Bogumily Muchy-Leszko
}

List of publications

1. Wlijanije wosproizwodstwiennoj struktury kapitalnych wlożenij na razwitje narodnowo chozjajstwa (w jęz. ros.), Wplyw reprodukcyjnej struktury nakładów inwestycyjnych na rozwój gospodarki narodowej, „Annales UMCS”, Sectio H Oeconomia, Vol. VIII, 1974, s. 77-88.

2. Problemy efektywności wykorzystania majątku trwatego $w$ dyskusji ekonomistów radzieckich, „Gospodarka Planowa” 1974, nr 4, s. 78-81.

3. Recenzja książki ekonomistów leningradzkich: Problemy wartości użytkowej, „Życie Gospodarcze”, nr 42 (1257), 19 X 1975, s. 4 (duże strony).

4. Kapitalnyje wlożenija $\boldsymbol{i}$ wosproizwodstwiennaja struktura narodnowo chozjajstwa (w jęz. ros.), Naklady inwestycyjne i reprodukcyjna struktura gospodarki narodowej, „Annales UMCS”, Sectio H Oeconomia, Vol. X, 1976, s. 25-39.

5. Podstawy ekonomii politycznej, cz. I. Przewodnik metodyczny dla słuchaczy kierunku społeczno-prawnego, zaocznego średniego studium zawodowego, Departament Szkolenia i Doskonalenia Zawodowego MSW, Warszawa 1977, ss. 62 (współautor P. Karpuś).

6. Podstawy ekonomii politycznej, cz. II. Przewodnik metodyczny dla słuchaczy kierunku społeczno-prawnego, zaocznego średniego studium zawodowego, Departament Szkolenia i Doskonalenia zawodowego MSW, Warszawa 1978, ss. 54 (współautor P. Karpuś).

7. Problemy rozwoju infrastruktury w gospodarce narodowej, praca zbiorowa pod red. W. Grzybowskiego, Wydawnictwo UMCS, Lublin 1979, s. 166, udział: rozdziały I-III, s. 5-109 (współautorzy: P. Karpuś, M. Zieliński).

8. Podzial kompetencji przy podejmowaniu decyzji cenowych, Prace i Materiały Zakładu Badania Cen, Państwowa Komisja Cen, Warszawa 1979, nr 52, s. 63-97 (współautorzy: W. Grzybowski, P. Karpuś).

9. Powstanie i ewolucja polityki regionalnej $w$ Stanach Zjednoczonych, „Annales UMCS”, Sectio H Oeconomia, Vol. XV/XVI, 1981/82, s. 49-63.

10. Polityka regionalna jako element interwencjonizmu państwowego w USA, Wydawnictwo UMCS, Lublin 1984.

11. Problemy tworzenia infrastruktury w procesie rozwoju spoleczno-ekonomicznego, „Annales UMCS”, Sectio H Oeconomia, Vol. XVIII, 1984, s. 9-28 (współautorzy: W. Grzybowski, P. Karpuś).

12. Rozwój polityki regionalnej w krajach Europy Zachodniej, „Annales UMCS”, Sectio H Oeconomia, Vol. XVIII, 1984, s. 178-199.

13. Ekonomia polityczna, tom I, skrypt pod red. W. Grzybowskiego, Wydawnictwo UMCS, Lublin 1986, s. 285, udział: s. 11-54, 134-139, 169-199 (rozdz. I - Przedmiot ekonomii politycznej, rozdz. II Procesy ksztaltowania się formacji spoleczno-ekonomicznych, rozdz. III - Ewolucja kapitalistycznych stosunków produkcji, rozdz. V pkt 8 - Powstanie i kryzys światowego systemu walutowego, rozdz. VII - Teoria wartości dodatkowej i dodatkowego produktu społecznego).

14. Recenzja Vol. XVII „Annales UMCS”, Sectio H Oeconomia, „Życie Szkoły Wyższej” 1986, nr 4, s. 165-169 (współautor P. Karpuś). 
15. Regiony regresyjne w gospodarce wysoko rozwiniętych krajów kapitalistycznych, [w:] Ekonomiści gospodarce narodowej, opracowanie zbiorowe pod red. W. Grzybowskiego, Wydawnictwo UMCS, Lublin 1987, s. 307-323.

16. Infrastruktura jako czynnik rozwoju spoleczno-gospodarczego, [w:] Ekonomiści gospodarce narodowej, opracowanie zbiorowe pod red. W. Grzybowskiego, Wydawnictwo UMCS, Lublin 1987, s. 325-335 (współautor P. Karpuś).

17. Infrastruktura barierą wzrostu gospodarczego, „Wektory” 1986, nr 2, s. $25-27$ duże strony (współautor P. Karpuś).

18. Sektor państwowy w gospodarce USA, ,Annales UMCS”, Sectio H Oeconomia, Vol. XXI, 1987, s. 91-105.

19. Tendencje rozwoju gospodarki PRL, „Annales UMCS”, Sectio H Oeconomia, Vol. XXI, 1987, s. 121-140 (współautor P. Karpuś).

20. Infrastruktura w makroregionach: poludniowym i środkowo-wschodnim, ,Annales UMCS”, Sectio H Oeconomia, Vol. XXIII, 1989, s. 117-125 (współautor A. Grabowiecka).

21. Aktualnyje prablemy razwitja Sybirii (w jęz. ros.), Aktualne problemy rozwoju Syberii, „Annales UMCS", Sectio H Oeconomia, Vol. XXIII, 1989, s. 487-492.

22. Ekonomia, praca zbiorowa pod red. W. Grzybowskiego, Wydawnictwo UMCS, Lublin 1990, s. 360, udział: s. 24-37, 123-225 ( rozdz. II - Teorie rozwoju społecznego, rozdz. VII - Etapy rozwoju gospodarki kapitalistycznej, rozdz. VIII - Ewolucja przedsiębiorstwa kapitalistycznego, rozdz. IX - Rynek w gospodarce kapitalistycznej, rozdz. X - Polityka pieniężna i system bankowy, rozdz. XI - Cykliczny rozwój gospodarki kapitalistycznej, rozdz. XII - Kapitalizm państwowo-monopolistyczny. Interwencjonizm państwowy).

23. Zachodnie prognozy spoteczno-ekonomiczne lat siedemdziesiatych, „Annales UMCS”, Sectio H Oeconomia, Vol. XXIV, 1990, s. 279-289.

24. Planowanie i prognozowanie w polityce spolecznej, [w:] T. Przeciszewski, B. Mucha-Leszko (red.), Wydawnictwo UMCS, Lublin 1990.

25. Prognozy spoteczno-ekonomiczne w literaturze zachodniej lat osiemdziesiatych, [w:] Planowanie i prognozowanie w polityce społecznej, T. Przeciszewski, B. Mucha-Leszko (red.), Wydawnictwo UMCS, Lublin 1990, s. 5-45.

26. Rola i miejsce Europejskiej Wspólnoty Gospodarczej w gospodarce światowej, Wydawnictwo UMCS, Lublin 1990 (współautorzy: W. Grzybowski, P. Karpuś), udział: rozdz. II (Regionalne dysproporcje $w$ gospodarce EWG, s. 31-42), rozdz. III (Polityka regionalna w krajach EWG, s. 43-60).

27. Międzynarodowe stosunki ekonomiczne, pod red. R.I. Chazbułatowa, Moskiewski Instytut Gospodarki Narodowej, Moskwa 1991, udział: Dysproporcje regionalne bariera w realizacji procesu integracji $w E W G$, rozdz. V pkt 4, s. 104-111 (w jęz. rosyjskim: Regionalnyje dyspraporcji kak barier realizacji procesa integracji w EGO, [w:] Mieżdunarodnyje Ekonomiczeskije Otnoszenija).

28. Wplyw procesów integracyjnych na rozwój regionalnych bloków gospodarczych, „Studia i Materiały Instytutu Ekonomii UMCS", tom I, Lublin 1991, s. 7-35.

29. Sektor publiczny i prywatyzacja w gospodarce krajów Europy Zachodniej, „Studia i Materiały Instytutu Ekonomii UMCS", tom I, Lublin 1991, s. 105-124.

30. Małe i średnie przedsiębiorstwa w realizacji polityki regionalnej, ,Studia i Materiały Instytutu Ekonomii Politycznej UMCS", tom I, Lublin 1991, s. 243-251.

31. Międzynarodowy rynek walutowy, [w:] Gospodarka światowa - wybrane problemy, B. Mucha-Leszko (red.), „Studia i Materiały Instytutu Ekonomii UMCS”, tom IV, Lublin 1992, s. 23-31.

32. Gospodarka światowa - wybrane problemy, B. Mucha-Leszko (red.), „Studia i Materiały Instytutu Ekonomii UMCS", tom IV, Lublin 1992.

33. Gospodarka światowa. Problemy rozwoju i wspótpracy, B. Mucha-Leszko (red.), „Studia i Materiały Instytutu Ekonomii UMCS", tom V, Lublin 1993.

34. Materialy do studiowania ekonomii, T. Tokarzewski (red.), Wydawnictwo Iunctim, Lublin 1993, s. 220, udział: rozdz. IV, Rynek w gospodarce, s. 71-86, rozdz. VII, System rachunku w skali społecznej 
i podstawowe kategorie i współzależności makroekonomiczne, s. 121-137 (współautorzy: S. Duda, H. Mamcarz, A. Pakuła).

35. Recesje w gospodarce Stanów Zjednoczonych po II wojnie światowej, [w:] Gospodarka światowa. Problemy rozwoju i wspótpracy, B. Mucha-Leszko (red.), „Studia i Materiały Instytutu Ekonomii UMCS", tom V, Lublin 1993, s. 9-22.

36. Regiony przygraniczne w gospodarce krajów rozwiniętych, [w:] Czynniki i bariery rozwoju regionów przygranicznych, J. Kitowski, Z. Zioło (red.), Materiały Konferencji Wydziału Ekonomicznego Filii UMCS w Rzeszowie, Sekcji Gospodarki Przestrzennej Oddziału PAN w Krakowie i Instytutu Gospodarki Przestrzennej i Komunalnej w Warszawie, Polańczyk 1993, s. 31-38.

37. Integracja europejska. Droga do unii ekonomicznej i monetarnej, Wydawnictwo UMCS, Lublin 1994 (współautor M. Ciepielewska).

38. Podstawy ekonomii, Lubelskie Towarzystwo Naukowe, Lublin 1994, s. 195, udział: rozdz. I, s. 11-26, Wprowadzenie do ekonomii, rozdz. XI, s. 174-194, Gospodarka światowa (współautorzy: S. Duda, H. Mamcarz, A. Pakuła).

39. Podstawy ekonomii, wyd. II, Zakład Poligraficzno-Wydawniczy „Znamirowski”, Lublin 1995, s. 195 (współautorzy: S. Duda, H. Mamcarz, A. Pakuła).

40. Handel zagraniczny Polski i powiązania gospodarcze ze światem, B. Mucha-Leszko (red.), „Studia i Materiały Instytutu Ekonomii UMCS", tom VIII, Lublin 1994.

41. Handel zagraniczny Polski na tle krajów CEFTA w latach 1990-1993, [w:] Handel zagraniczny Polski i powiazania gospodarcze ze światem, B. Mucha-Leszko (red.), „Studia i Materiały Instytutu Ekonomii UMCS", tom VIII, Lublin 1994, s. 25-47.

42. Lagodzenie dysproporcji regionalnych w gospodarce rynkowej, doświadczenia Unii Europejskiej, [w:] Problemy transformacji regionalnych $w$ procesie przechodzenia do gospodarki rynkowej, J. Kitowski, Z. Zioło (red.), Materiały z Konferencji Sekcji Gospodarki Przestrzennej Komisji Nauk Ekonomicznych Oddziału w Krakowie, Wydziału Ekonomicznego Filii UMCS w Rzeszowie pod patronatem KPZK PAN w Warszawie, Warszawa, Kraków, Rzeszów 1994, s. 139-153.

43. Subsidiarity and the Committee of the Regions Competence, [in:] Papers of the Symposium of Jean Monnet Chairs on the 1996 Intergovernmental Conference, European Commission DG X, Brussels 1996.

44. Biuletyn Europejski 1995, B. Mucha-Leszko (red.), Wydawnictwo UMCS, Lublin 1996.

45. Biala księga - czyli strategia integracji krajów Europy Środkowo-Wschodniej z Jednolitym Rynkiem $\boldsymbol{U E}$, [w:] Biuletyn Europejski 1995, B. Mucha-Leszko (red.), Wydawnictwo UMCS, Lublin 1996, s. $47-65$.

46. Biuletyn Europejski 1996, B. Mucha-Leszko (red.), Wydawnictwo UMCS, Lublin 1997.

47. Stosunki Wspólnota Europejska - kraje Afryki, Karaibów i Pacyfiku (IV Konwencja z Lomé-1989 i 1995), [w:] Biuletyn Europejski 1996, B. Mucha-Leszko (red.), Wydawnictwo UMCS, Lublin 1997, s. 73-100.

48. Spoleczno-ekonomiczne aspekty procesu dostosowywania gospodarki Polski do standardów Unii Europejskiej, B. Mucha-Leszko (red.), Wydawnictwo UMCS, Lublin 1997, s. 194 (współautorzy: P. Baliński, M. Ciepielewska, J. Kuśpit), udział autorski: Proces integracji Polski z Unia Europejska, rozdz. I, s. 11-24; Analiza wskaźników makroekonomicznych, rozdz. II pkt 1, s. 25-36; Struktura gospodarki Polski na tle krajów Unii Europejskiej, rozdz. IV pkt 1, s. 81-88.

49. Wplyw transformacji systemowej w Polsce na nowy uktad stosunków gospodarczych z zagranica, [w:] Szanse i zagrożenia procesu transformacji systemowej gospodarki Polski, W. Grzybowski (red.), Wydawnictwo UMCS, Lublin 1998, s. 87-95.

50. Integracja regionalna w warunkach globalizacji procesów gospodarczych. Szanse Unii Europejskiej w policentrycznym ukladzie światowym, [w:] Bariery i stymulatory integracji europejskiej, H. Przybylski (red.), tom 2, Wydawnictwo Akademii Ekonomicznej, Katowice 1998, s. 161, udział autorski: s. $27-37$.

51. Biuletyn Europejski 1997, B. Mucha-Leszko (red.), Wydawnictwo UMCS, Lublin 1998. 
52. Zagraniczna polityka ekonomiczna Unii Europejskiej, [w:] Biuletyn Europejski 1997, B. Mucha-Leszko (red.), Wydawnictwo UMCS, Lublin 1998, s. 47-62.

53. Stosunki EWG-EFTA. Europejski Obszar Gospodarczy, [w:] Biuletyn Europejski 1997, B. MuchaLeszko (red.), Wydawnictwo UMCS, Lublin 1998, s. 63-70.

54. Polityka handlowa Unii Europejskiej wobec krajów Basenu Morza Śródziemnego, [w:] Biuletyn Europejski 1997, B. Mucha-Leszko (red.), Wydawnictwo UMCS, Lublin 1998, s. 91-103.

55. Rozwój wspótpracy Unii Europejskiej z krajami Afryki, Karaibów i Pacyfiku, [w:] Biuletyn Europejski 1997, B. Mucha-Leszko (red.), Wydawnictwo UMCS, Lublin 1998 (zaktualizowana wersja opracowania opublikowanego w Biuletynie Europejskim 1996), s. 117-148.

56. Recenzja książki H., Grabbe i K. Hughes Enlarging the EU Eastwards, wydanej przez The Royal Institute of International Affairs, London 1998, [w:] B. Mucha-Leszko (red.), Biuletyn Europejski 1997, Wydawnictwo UMCS, Lublin 1998, s. 241-246.

57. Polityka handlowa Unii Europejskiej wobec krajów trzecich, B. Mucha-Leszko (red.), Wydawnictwo Małopolskiego Instytutu Gospodarczego, Rzeszów 1999, s. 254 (zmieniona wersja Biuletynu Europejskiego 1997).

58. Ogólne zasady zagranicznej polityki ekonomicznej Unii Europejskiej, [w:] Polityka handlowa Unii Europejskiej wobec krajów trzecich, B. Mucha-Leszko (red.), Wydawnictwo Małopolskiego Instytutu Gospodarczego, Rzeszów 1999, s. 11-26.

59. Stosunki EWG-EFTA. Europejski Obszar Gospodarczy, [w:] Polityka handlowa Unii Europejskiej wobec krajów trzecich, B. Mucha-Leszko (red.), Wydawnictwo Małopolskiego Instytutu Gospodarczego, Rzeszów 1999, s. 27-43.

60. Polityka handlowa Unii Europejskiej wobec krajów Basenu Morza Śródziemnego, [w:] Polityka handlowa Unii Europejskiej wobec krajów trzecich, B. Mucha-Leszko (red.), Wydawnictwo Małopolskiego Instytutu Gospodarczego, Rzeszów 1999, s. 67-79.

61. Rozwój wspótpracy Unii Europejskiej z krajami Afryki, Karaibów i Pacyfiku, [w:] Polityka handlowa Unii Europejskiej wobec krajów trzecich, B. Mucha-Leszko (red.), Wydawnictwo Małopolskiego Instytutu Gospodarczego, Rzeszów 1999, s. 93-133.

62. Integracja regionalna w warunkach globalizacji procesów gospodarczych. Szanse Unii Europejskiej w policentrycznym ukladzie światowym, [w:] Polityka handlowa Unii Europejskiej wobec krajów trzecich, B. Mucha-Leszko (red.), Wydawnictwo Małopolskiego Instytutu Gospodarczego, Rzeszów 1999, s. $215-225$.

63. Socio-Economic Aspects of Poland's Adjustment towards the European Union Standards, B. Mucha-Leszko (ed.), Maria Curie-Sklodowska University Press, Lublin,1999, Language, Culture and Society. A Library of Textbooks for Foreign Students, s. 210.

64. The process of Poland's integration with the European Union, [in:] Socio-Economic Aspects of Poland's Adjustment towards the European Union Standards, B. Mucha-Leszko (ed.), Maria Curie-Sklodowska University Press, Lublin,1999, Language, Culture and Society. A Library of Textbooks for Foreign Students, s. 13-25.

65. The fulfilment of membership conditions in the area of economic adjustment, [in:] Socio-Economic Aspects of Poland's Adjustment towards the European Union Standards, B. Mucha-Leszko (ed.), Maria Curie-Sklodowska University Press, Lublin,1999, Language, Culture and Society. A Library of Textbooks for Foreign Students, s. 27-44 (współautor P. Baliński).

66. Structural aspects of the adjustment process of Poland's economy to integration with the European Union, [in:] Socio-Economic Aspects of Poland's Adjustment towards the European Union Standards, B. Mucha-Leszko (ed.), Maria Curie-Sklodowska University Press, Lublin 1999, Language, Culture and Society. A Library of Textbooks for Foreign Students, s. 75-128 (współautor M. Ciepielewska).

67. Wzrost gospodarczy, bezrobocie i inflacja w krajach UE w latach 1960-1995, [w:] Bariery i szanse rozwoju gospodarki rynkowej w Polsce, R. Orłowski (red.), Wydawnictwo UMCS, Lublin 1999, s. 131-146.

68. Biuletyn Europejski 1998. Polityka spoteczno-ekonomiczna Unii Europejskiej. Zakres, sektory, dziedziny, B. Mucha-Leszko (red.), Wydawnictwo UMCS, Lublin 1999. 
69. Wspólna polityka przemystowa, [w:] Biuletyn Europejski 1998. Polityka społeczno-ekonomiczna Unii Europejskiej. Zakres, sektory, dziedziny, B. Mucha-Leszko (red.), Wydawnictwo UMCS, Lublin 1999, s. $171-190$.

70. Wspólna polityka w dziedzinie badań naukowych i technologii, [w:] Biuletyn Europejski 1998. Polityka społeczno-ekonomiczna Unii Europejskiej. Zakres, sektory, dziedziny, B. Mucha-Leszko (red.), Wydawnictwo UMCS, Lublin 1999, s. 191-216 (współautorzy: B. Jóźwik, M. Kąkol).

71. Wspólna polityka w dziedzinie konkurencji, [w:] Biuletyn Europejski 1998. Polityka społeczno-ekonomiczna Unii Europejskiej. Zakres, sektory, dziedziny, B. Mucha-Leszko (red.), Wydawnictwo UMCS, Lublin 1999, s. 303-326.

72. Od wspólnej polityki walutowej do euro, [w:] Biuletyn Europejski 1998. Polityka społeczno-ekonomiczna Unii Europejskiej. Zakres, sektory, dziedziny, B. Mucha-Leszko (red.), Wydawnictwo UMCS, Lublin 1999, s. 365-410 (współautor A. Jarosz).

73. Globalizacja a perspektywy rozwoju gospodarki światowej w świetle opracowań OECD, „Annales UMCS", Sectio H Oeconomia, Vol. XXXIV, Lublin 2000, s. 163-176.

74. Sytuacja na rynku pracy jako priorytetowy problem polityki społecznej Unii Europejskiej, [w:] SpoŁeczna gospodarka rynkowa w Polsce, S. Partycki (red.), Materiały III Międzynarodowej Konferencji Socjologicznej, Nałęczów 15-17 czerwca 2000 r., Wydawnictwo UMCS, Lublin 2000, s. 333-341.

75. Gospodarka światowa. Handel zagraniczny i marketing, praca zbiorowa, B. Mucha-Leszko (red.), Wydawnictwo UMCS, Lublin 2003, s. 361.

76. Rozwój powiazań w gospodarce światowej-etapy globalizacji i regionalizacja procesów gospodarczych, [w:] Gospodarka światowa. Handel zagraniczny i marketing, praca zbiorowa, B. Mucha-Leszko (red.), Wydawnictwo UMCS, Lublin 2003, s. 13-94.

77. Rozszerzenie Unii Europejskiej na Wschód - realia i perspektywy, [w:] Gospodarka światowa. Handel zagraniczny i marketing, praca zbiorowa, B. Mucha-Leszko (red.), Wydawnictwo UMCS, Lublin 2003, s. 95-113 (współautor J. Kuśpit).

78. Rola Banku Rozrachunków Międzynarodowych w Bazylei jako instytucji międzynarodowej, [w:] Gospodarka światowa. Handel zagraniczny i marketing, praca zbiorowa, B. Mucha-Leszko (red.), Wydawnictwo UMCS, Lublin 2003, s. 165-188 (współautorzy: K. Kaszuba i M. Kąkol).

79. The economic situation of the Euro area on the background of present tendencies in the economies of the United States and Japan, [w:] Europe: reunification, enlargement, single currency, Angelo Santagostino (ed.), Edicioni CLUB - Cooperativa Libraria Universitaria Bresciana 2003, s. 159, udział: s. 113-127 (współautor M. Kąkol).

80. The economic situation of the Euro area on the background of present tendencies in the economies of the United States and Japan, [w:] The Euro and Enlargement. A Single Currency for Reunified Europe, Biuletyn Europejski 2001, B. Mucha-Leszko (ed.), Wydawnictwo UMCS, Lublin 2004, s. $11-31$.

81. Ekonomiczne przesłanki czlonkostwa Polski w Unii Europejskiej, [w:] Zjednoczona Europa a Polska, Litwa i Ukraina, L. Gawor (red.), Materiały z Konferencji Międzynarodowej pt. Miejsce Polski i krajów Europy Środkowej w strukturach unijnych, Lublin 11-13 kwietnia 2003 r., Wydawnictwo UMCS, Lublin 2003, s. 104-116.

82. Protekcjonistyczne aspekty polityki handlowej Unii Europejskiej w dziedzinie artykutów rolno-spozywczych, Biuletyn Europejski 1999/2000 (redaktor naukowy serii wydawniczej B. Mucha-Leszko), Wydawnictwo UMCS, Lublin 2003, autor A. Jarosz-Angowska, s. 362.

83. The Euro and Enlargement. A Single Currency for Reunified Europe, Biuletyn Europejski 2001, B. Mucha-Leszko (ed.), Wydawnictwo UMCS, Lublin 2004, s. 181.

84. Ewolucja wspólnej polityki rolnej UE-przesłanki i uwarunkowania zmian systemowych, ,Annales UMCS", Sectio H Oeconomia, Vol. XXXVIII, Lublin 2004, s. 25-44.

85. Rola polityki regionalnej w procesie integracji europejskiej, Biuletyn Europejski 2002 (redaktor naukowy serii wydawniczej B. Mucha-Leszko), Wydawnictwo UMCS, Lublin 2004 (autor A. Maciaszczyk), s. 345. 
86. The independence principle in the policy of the European Central Bank, Journal of the European Economy, Ternopil Academy of National Economy, Vol. 3 (No. 4), December 2004, s. 413-427 (współautor O. Honchar, praca ta została opublikowana również w rosysyjskojęzycznej wersji: Pryncyp Niezawisimosti i jewo realizacja w politikie Jewropejskowo Centralnowo Banka, Żurnal Jewropejskoj Ekonomiki, tom 3, nr 4, Dekabr 2004, s. 457-473).

87. Unia Europejska w systemie gospodarki globalnej, [w:] Nauki ekonomiczne wobec problemów wspótczesnej gospodarki, J. Węcławski (red.), Księga jubileuszowa z okazji 40-lecia Wydziału Ekonomicznego UMCS, Wydawnictwo UMCS, Lublin 2005, s. 109-134.

88. Wspótczesna gospodarka światowa. Gtówne centra gospodarcze, praca zbiorowa, B. Mucha-Leszko (red.), Wydawnictwo UMCS, Lublin 2005, s. 360.

89. Rozwój powiązań w gospodarce światowej - etapy globalizacji i regionalizacja procesów gospodarczych, [w:] Wspótczesna gospodarka światowa. Główne centra gospodarcze, praca zbiorowa, B. Mucha-Leszko (red.), Wydawnictwo UMCS, Lublin 2005 (zaktualizowana wersja opracowania opublikowanego w roku 2003), s. 15-114.

90. Znaczenie euro jako waluty światowej, [w:] Współczesna gospodarka światowa. Główne centra gospodarcze, praca zbiorowa, B. Mucha-Leszko (red.), Wydawnictwo UMCS, Lublin 2005, s. 169-202 (współautor M. Kąkol).

91. Unia Europejska w systemie gospodarki globalnej, [w:] Współczesna gospodarka światowa. Główne centra gospodarcze, praca zbiorowa, B. Mucha-Leszko (red.), Wydawnictwo UMCS, Lublin 2005, s. $141-168$.

92. Rozwój powiązań handlowych i inwestycyjnych Japonii i Stanów Zjednoczonych, [w:] Wspótczesna gospodarka światowa. Główne centra gospodarcze, praca zbiorowa, B. Mucha-Leszko (red.), Wydawnictwo UMCS, Lublin 2005, s. 233-264 (współautor T. Białowąs).

93. Pomoc państwa jako forma interwencji na rynku wewnętrznym Unii Europejskiej, [w:] Lad gospodarczy jako efekt działalności państwa w społecznej gospodarce rynkowej, Oddział Warszawski PTE, Warszawa 2005, s. 85-101 (współautor M. Kąkol).

94. Competition policy - process and forms of its internationalization. Publikacja elektroniczna z Międzynarodowej Konferencji pt. The Channels of European Integration, Warsaw School of Economics, Institute of International Economics, University of Tübingen, Department of Economics, Institute of Applied Economic Research, Tübingen, 7-8 October 2005, Warsaw, s. 15 (współautor M. Kąkol).

95. Wspieranie rozwoju malych i średnich przedsiębiorstw przez Grupę Europejskiego Banku Inwestycyjnego, [w:] Szanse rozwoju polskiego sektora MŚP na Jednolitym Rynku Europejskim (Wspieranie rozwoju MŚP na Jednolitym Rynku Europejskim, tom 2), J. Otto, R. Stanisławski (red.), Wydawnictwo Politechniki Łódzkiej, Łódź 2006, s. 60-72.

96. Systemy wspierania eksportu w Unii Europejskiej a międzynarodowa polityka handlowa, Biuletyn Europejski 2003 (redaktor naukowy serii wydawniczej B. Mucha-Leszko), Wydawnictwo UMCS, Lublin 2006, ss. 121.

97. Problem subsydiów w międzynarodowej polityce handlowej, [w:] Systemy wspierania eksportu w Unii Europejskiej a międzynarodowa polityka handlowa, B. Mucha-Leszko (red.), Biuletyn Europejski 2003, Wydawnictwo UMCS, Lublin 2006, s. 13-36.

98. Recenzja książki Anne Stevens with Handley Stevens: Brussels Bureaucrats? The Administration of the European Union, The European Series, Palgrave, [w:] Systemy wspierania eksportu w Unii Europejskiej a międzynarodowa polityka handlowa, B. Mucha-Leszko (red.), Biuletyn Europejski 2003, Wydawnictwo UMCS, Lublin 2006, s. 109-121.

99. Zasady pomocy regionalnej Unii Europejskiej a možliwości rozwoju województwa lubelskiego, [w:] Regionalne aspekty społecznej gospodarki rynkowej, Cz. Skowronek (red.), Oddział Warszawski PTE, Warszawa 2006, ss. 163, udział: s. 75-101 (współautor M. Kąkol).

100. Poland in the European Union - Experience of the First Years of Membership, Biuletyn Europejski 2004/2005 (redaktor naukowy serii wydawniczej B. Mucha-Leszko), Wydawnictwo UMCS, Lublin 2006, ss. 196. 
101. State aid in the adjustment process of Poland's economy to the EU common market, [w:] B. Mucha-Leszko (red.), Poland in the European Union - Experience of the First Years of Membership, Biuletyn Europejski 2004/2005, Wydawnictwo UMCS, Lublin 2006, s. 11-29 (współautor M. Kąkol).

102. Compliance by Poland with the EU rules concerning State aid, [w:] B. Mucha-Leszko (red.), Poland in the European Union - Experience of the First Years of Membership, Biuletyn Europejski 2004/2005, Wydawnictwo UMCS, Lublin 2006, s. 31-58 (współautor M. Kąkol).

103. State aid as a market intervention instrument of the EU new member countries (cases of Poland, the Czech Republic and Hungary), The Influence of the Globalization Processes on Central and Eastern European Region, „Working Papers, Institute of International Business, University of Gdańsk”, No. 22, Fundacja Rozwoju Uniwersytetu Gdańskiego, Sopot 2006, s. 248-263 (współautor M. Kąkol).

104. 50 lat traktatów rzymskich. Sukcesy i trudne realia integracji europejskiej, Biuletyn Europejski, wydanie specjalne (redaktor naukowy serii wydawniczej B. Mucha-Leszko), Wydawnictwo UMCS, Lublin 2007, ss. 196.

105. Próby budowania wspólnej Europy w latach 40. XX wieku - koncepcje i inicjatywy, [w:] 50 lat traktatów rzymskich. Sukcesy i trudne realia integracji europejskiej, B. Mucha-Leszko (red.), Biuletyn Europejski, wydanie specjalne, Wydawnictwo UMCS, Lublin 2007, s. 17-44.

106. Pomoc dla regionów stabo rozwiniętych z funduszy UE a szanse aktywizacji gospodarczej województwa lubelskiego, ,Zamojskie Studia i Materiały”, (24) 2007, seria: Ekonomia (3), Wyższa Szkoła Zarządzania i Administracji w Zamościu, Zamość 2007, s. 147-170 (współautor M. Kąkol).

107. Strefa euro. Wprowadzanie, funkcjonowanie, międzynarodowa rola euro, Wydawnictwo UMCS, Lublin 2007, ss. 385.

108. Pozycja strefy euro w gospodarce światowej, [w:] Problemy gospodarki światowej, „Prace Naukowe Akademii Ekonomicznej im. Oskara Langego we Wrocławiu", nr 1191, Wydawnictwo AE we Wrocławiu, 2008, s. 348-362.

109. Pomoc państwowa w polityce konkurencji w Unii Europejskiej, Biuletyn Europejski 2006/2007 (redaktor naukowy serii wydawniczej B. Mucha-Leszko), Wydawnictwo UMCS, Lublin 2007 (autor M. Kąkol), ss. 340.

110. Miejsce Unii Europejskiej w zagranicznej ekspansji gospodarczej Japonii, Biuletyn Europejski 2008 (redaktor naukowy serii wydawniczej B. Mucha-Leszko), Wydawnictwo UMCS, Lublin 2008 (autor P. Pasierbiak), ss. 347.

111. Priority areas of the EU external economic policy under globalization, „Working Papers Institute of International Business University of Gdańsk" Meeting Global Challenges, No. 25, Wydawnictwo Fundacja Rozwoju Uniwersytetu Gdańskiego, Sopot 2008, s. 24-41 (współautor M. Kąkol).

112. Gtówne czynniki niskiego tempa wzrostu gospodarczego w strefie euro w latach 1999-2007, [w:] Polityka wzrostu gospodarczego w Polsce i w Unii Europejskiej. Polityka ekonomiczna a wzrost gospodarczy, J.L. Bednarczyk, S.I. Bukowski, W. Przybylska-Kapuścińska (red.), Wydawnictwo CeDeWu, Warszawa 2008, s. 41-58 (współautor M. Kąkol).

113. Ewolucja idei zjednoczenia Europy, [w:] Między historia a teraźniejszościa, E. Skrzypek, Z. Szymański (red.), Wydawnictwo UMCS, Lublin 2008, s. 107-129.

114. Polityka Systemu Rezerwy Federalnej USA i jej skutki w latach 1995-2008, [w:] Wspótczesny kryzys gospodarczy. Przyczyny, przebieg, skutki, J.L. Bednarczyk, S.I. Bukowski, J. Misala (red.), Wydawnictwo CeDeWu, Warszawa 2009, s. 45-66 (współautor M. Kąkol).

115. Pozycja Unii Europejskiej w handlu międzynarodowym. Dynamika i struktura obrotów, konkurencyjność, główni partnerzy, B. Mucha-Leszko (red.), Wydawnictwo UMCS, Lublin 2009, ss. 218.

116. Analiza handlu towarami Unii Europejskiej w latach 1995-2008 i ocena konkurencyjności, [w:] Pozycja Unii Europejskiej w handlu międzynarodowym. Dynamika i struktura obrotów, konkurencyjność, główni partnerzy, B. Mucha-Leszko (red.), Wydawnictwo UMCS, Lublin 2009, s. 19-50 (współautorzy: M. Kąkol, T. Białowąs).

117. Analiza handlu ustugami Unii Europejskiej w latach 1995-2008 i ocena konkurencyjności, [w:] Pozycja Unii Europejskiej w handlu międzynarodowym. Dynamika i struktura obrotów, konkurencyjność, 
główni partnerzy, B. Mucha-Leszko (red.), Wydawnictwo UMCS, Lublin 2009, s. 51-92 (współautorzy: M. Kąkol, T. Białowąs).

118. Stosunki handlowe Unii Europejskiej z Japonia w latach 1995-2007, [w:] Pozycja Unii Europejskiej w handlu międzynarodowym. Dynamika i struktura obrotów, konkurencyjność, główni partnerzy, B. Mucha-Leszko (red.), Wydawnictwo UMCS, Lublin 2009, s. 181-218 (współautorzy: T. Białowąs, M. Kąkol).

119. Procesy migracyjne po ostatnim rozszerzeniu Unii Europejskiej, „Polityka Społeczna”, nr 8/2009, Instytut Pracy i Spraw Socjalnych, Warszawa 2009, s. 9-13 (współautor M. Kąkol).

120. Wzrost znaczenia i formy międzynarodowej polityki konkurencji, „Gospodarka Narodowa”, nr 5-6/2009, SGH, Warszawa 2009, s. 21-38 (współautor M. Kąkol).

121. Jak funkcjonowanie w strefie euro wplywa na stabilizację gospodarcza jej krajów czlonkowskich?, „Prace Naukowe Uniwersytetu Ekonomicznego we Wrocławiu. Problemy ekonomii, polityki ekonomicznej i finansów publicznych", nr 39, tom 1, 2009, s. 247-255.

122. Will the financial economic crisis of 2008-2009 accelerate monetary integration in the EU?, [w:] Europe and its economic frontier, L. Soproni, A. Santagostino, E. Molnar (red.), University of Oradea, University of Debrecen, „Eurolimes”, Vol. 8, 2009, s. 17-31 (współautor M. Kąkol).

123. Kryzys finansowo-gospodarczy a przyspieszenie integracji walutowej. Opinia ekspercka przygotowana dla Przedstawicielstwa Komisji Europejskiej w Polsce, [w:] Pytania o Europę. Opinie ekspertów, Wydawnictwo Komisja Europejska Przedstawicielstwo w Polsce, Warszawa 2010, s. 158-163.

124. Recenzja ksiazki M. Piotrowska, L. Kurowski (red.), Global Challenges and Policies of the European Union-Consequences for the „New Member States”, WUE 2009, 484 pp., „Argumenta Oeconomica” No. 2 (25), 2010, Wrocław University of Economics, s. 177-179.

125. Znaczenie polityki energetycznej w procesie integracji europejskiej, Biuletyn Europejski 2009/ 2010 (redaktor naukowy serii wydawniczej B. Mucha-Leszko), Wydawnictwo UMCS, Lublin 2008, autor A. Gawlikowska-Fyk, ss. 244.

126. Kryzys finansowy a perspektywy strefy euro, „Euro Express”, czasopismo studiów podyplomowych „Mechanizmy funkcjonowania strefy euro”, nr 1, rok ak. 2009/2010, Uniwersytet Rzeszowski 2010, s. 2-3 (współautor M. Kąkol).

127. Relacja z Brussels Economic Forum 2010, „Wiadomości Uniwersyteckie”, nr 8/167, UMCS, październik 2010, s. 34-35 (duże strony), (współautor M. Kąkol).

128. Pozycja innowacyjna krajów strefy euro w skali globalnej, [w:] Transfer wiedzy i funduszy europejskich do sektorów gospodarki krajów Unii Europejskiej, J. Stacharska-Targosz, J. Szostak (red.), Wydawnictwo Wyższej Szkoły Bankowej w Poznaniu, Poznań 2010, s. 209-221 (współautor M. Kąkol).

129. Euro - waluta regionalna czy globalna?, [w:] Wyzwania gospodarki globalnej, „Prace i Materiały Instytutu Handlu Zagranicznego Uniwersytetu Gdańskiego", nr 28/1, Fundacja Rozwoju Uniwersytetu Gdańskiego, Sopot 2010, s. 444-473 (współautor M. Kąkol).

130. Przyczyny i skutki zróżnicowania konkurencyjności w strefie euro, [w:] Dylematy kreowania wartości przedsiębiorstw w okresie wychodzenia z kryzysu, „Prace i Materiały Wydziału Zarządzania Uniwersytetu Gdańskiego", nr 4/2, 2010, Wydział Zarządzania UG i Fundacja Rozwoju UG, Sopot 2010, s. 361-377 (współautor M. Kąkol).

131. Konwergencja realna i doświadczenia strefy euro a wspólna waluta w Polsce, [w:] Polska w Unii Europejskiej-doświadczenia i wyzwania, „Problemy Zarządzania”, vol. 8, nr 1 (27), Wydział Zarządzania UW, wiosna 2010, s. 20-46.

132. Podstawy teoretyczne i realizacja polityki fiskalnej w strefie euro, „Annales UMCS”, Sectio H Oeconomia, Vol. 44, Wydawnictwo UMCS, Lublin 2010, s. 81-102 (współautor M. Kąkol).

133. Rozwój infrastruktury a proces konwergencji gospodarczej, Nierówności spoleczne a wzrost gospodarczy, Uniwersytet Rzeszowski, Katedra Teorii Ekonomii i Stosunków Międzynarodowych, Rzeszów 2010, s. 127-139 (współautor M. Kąkol).

134. EU economic frontiers determined by its international trade position and trade Policy, [in:] The Geopolitics of European Frontiers, D.I. Dolghi (ed.), „Eurolimes”, Vol. 10, Autumn 2010, University of Oradea \& University of Debrecen, s. 151-162 (współautor M. Kąkol). 
135. Gospodarka i polityka makroekonomiczna strefy euro w latach 2008-2010. Skutki kryzysu i stabości zarządzania, B. Mucha-Leszko (red.), Wydawnictwo UMCS, Lublin 2011.

136. Od kryzysu finansowego do kryzysu finansów publicznych, czyli skutki polityki fiskalnej w strefie euro w latach 2008-2010, [w:] Gospodarka i polityka makroekonomiczna strefy euro w latach 2008-2010. Skutki kryzysu i słabości zarzadzania, B. Mucha-Leszko (red.), Wydawnictwo UMCS, Lublin 2011, s. 221-262 (współautor M. Kąkol).

137. Rozszerzanie i perspektywy strefy euro, [w:] Mechanizmy funkcjonowania strefy euro, I. Politowicz, Z. Binek (red.), Oficyna Wydawnicza Uniwersytetu Zielonogórskiego, Zielona Góra 2011 (współautor M. Kąkol).

138. Portugalia w unii walutowej-problemy gospodarcze i kryzys finansów publicznych, „Ekonomista”, nr 4, 2011 (współautor M. Kąkol).

139. Prowzrostowe efekty polityki fiskalnej w strefie euro w latach 2008-2010 i jej skutki dla finansów publicznych, „Euro Express”, czasopismo studiów podyplomowych „Mechanizmy funkcjonowania strefy euro", nr 2, rok ak. 2010/2011, Uniwersytet Rzeszowski.

140. Pozycja i rola Unii Europejskiej w globalnym ukladzie sil, [w:] Wyzwania gospodarki globalnej, „Prace i Materiały Instytutu Handlu Zagranicznego”, nr 31, Fundacja Rozwoju Uniwersytetu Gdańskiego, Sopot 2012, s. 276-296 (współautor M. Kąkol).

141. Polityka handlowa w warunkach Pax Americana i Pax Britannica, „Annales UMCS”, Sectio H Oeconomia, Vol. XLVI, nr 2, 2012, s. 153-163 (współautor M. Kąkol).

142. Policentryzacja ukladu sil gospodarczych a multilateralna polityka handlowa, „Annales UMCS”, Sectio H Oeconomia, Vol. XLVI, nr 2, 2012, s. 165-174.

143. Przyszłość strefy euro - ściślejsza integracja czy powrót do dwóch prędkości?, „Acta Universitatis Lodzienis. Folia Oeconomica", nr 273, 2012, s. 301-316.

144. Globalizacja i zmiany w uktadzie sil gospodarczych a międzynarodowy system walutowy, [w:] Globalizacja i regionalizacja we współczesnym świecie, Księga jubileuszowa dedykowana Profesor Irenie Pietrzyk, E. Molendowski (red.), Wydawnictwo Uniwersytetu Ekonomicznego, Kraków 2012, s. 313-322 (współautor M. Kąkol).

145. Polityka fiskalna i sytuacja w dziedzinie finansów publicznych Danii, Szwecji i Wielkiej Brytanii w latach 1999-2012, [w:] Stabilizacja fiskalna - teorie i doświadczenia wybranych gospodarek, D. Miłaszewicz (red.), Wydawnictwo Uniwersytetu Szczecińskiego, Szczecin 2012, s. 139-157 (współautor M. Wojtas).

146. Korzyści międzynarodowej integracji gospodarczej a osiagnięcia i problemy Unii Europejskiej, [w:] Przyszłość integracji europejskiej - konkurencyjność i rynki, W. Bieńkowski, S.I. Bukowski, G. Olszewska (red.), Wydawnictwo CeDeWu, Warszawa 2012, s. 15-42.

147. Perspektywy euro jako waluty międzynarodowej, [w:] Współczesne problemy ekonomiczne. Wybrane zagadnienia teoretyczne a praktyka gospodarcza, „Studia Ekonomiczne”, nr 129, Katowice 2013, s. 97-106 (współautor M. Kąkol).

148. Hiszpania w unii walutowej, „Annales UMCS”, Sectio H Oeconomia, Vol. 47, nr 1, 2013, s. 107-120.

149. Efektywność automatycznych stabilizatorów koniunktury w Unii Europejskiej, „Annales UMCS”, Sectio H Oeconomia, Vol. 47, nr 2, 2013, s. 123-132 (współautor M. Kąkol).

150. Polityka integracyjna Francji-motywy, koncepcje, rezultaty, „Annales UMCS”, Sectio H Oeconomia, Vol. 47, nr 2, 2013, s. 165-178.

151. Możliwości zmniejszania luki rozwojowej Polski w Unii Europejskiej i wobec krajów o największym potencjale gospodarczym w perspektywie 2040 roku, „Zarządzanie i Finanse”, Vol. 11, nr 1, 2013.

152. Znaczenie i perspektywy euro w funkcji waluty rezerwowej, „Annales UMCS”, Sectio H Oeconomia, Vol. 48, nr 1, 2014, s. 151-160.

153. Richard Coudenhove-Kalergi jako autor koncepcji unii federalnej oraz inicjator procesów integracyjnych w Europie, „Annales UMCS”, Sectio H Oeconomia, Vol. 48, nr 2, 2014, s. 69-78 (współautor A. Jarosz-Angowska).

154. Globalna czy regionalna liberalizacja handlu międzynarodowego?, „Zeszyty Naukowe Uniwersytetu Szczecińskiego. Współczesne Problemy Ekonomiczne. Globalizacja. Liberalizacja. Etyka”, nr 8 (2014), Wydawnictwo Naukowe Uniwersytetu Szczecińskiego, Szczecin 2014, s. 143-154. 
Pobrane z czasopisma Annales $\mathrm{H}$ - Oeconomia http://oeconomia.annales.umcs.pl Data: 26/04/2023 13:04:59

155. Wyniki gospodarcze Szwecji w latach 2000-2013 a problem wprowadzenia euro, „Annales UMCS”, Sectio H Oeconomia, Vol. 49, nr 1, 2015 (współautor M. Kąkol).

156. „Eurolimes” Journal of the Institute for Euroregional Studies Oradea-Debrecen, The Social Frontiers of Europe, Vol. 17, Spring 2014, Oradea University Press (współredakcja naukowa).

157. Welfare States in Europe or the European Welfare State, „Eurolimes” Journal of the Institute for Euroregional Studies Oradea-Debrecen, The Social Frontiers of Europe, Vol. 17, Spring 2014, Oradea University Press, s. 33-47 (współautor M. Kąkol).

158. Pozycja gospodarcza Polski w Unii Europejskiej, B. Mucha-Leszko (red.), Wydawnictwo UMCS, Lublin 2014.

159. Wzrost gospodarczy i proces konwergencji oraz średnio- i dlugoterminowe perspektywy zmniejszania luki rozwojowej, [w:] Pozycja gospodarcza Polski w Unii Europejskiej, B. Mucha-Leszko (red.), Wydawnictwo UMCS, Lublin 2014.

160. Polityka budżetowa i sytuacja w dziedzinie finansów publicznych, [w:] Pozycja gospodarcza Polski w Unii Europejskiej, B. Mucha-Leszko (red.), Wydawnictwo UMCS, Lublin 2014.

Zestawienie publikacji przygotowała:

Katarzyna Twarowska 